\title{
Using multiple criteria decision making models for ranking customers of bank network based on loyalty properties in weighted RFM model
}

\author{
Fayegh Zaheri $^{a^{*}}$, Hiwa Farughi ${ }^{\mathrm{c}}$, Hersh Soltanpanah $^{\mathrm{a}}$, Seiran Alaniazar ${ }^{\mathrm{b}}$, and Foruzan Naseri ${ }^{\mathrm{c}}$
}

${ }^{a}$ Department of Industrial Engineering, Sanandaj Branch,Islamic Azad University, Sanandaj, Iran

${ }^{b}$ Young researchers club, Sanandaj Branch,Islamic Azad University, Sanandaj, Iran

${ }^{c}$ Department of Industrial Engineering, University Of Kurdistan, Sanandaj, Iran

\section{A R T I C L E I N F O \\ A B S T R A C T}

\section{Article history:}

Received December 16, 2011

Received in Revised form

January, 3, 2012

Accepted 10 January 2012

Available online

16 January 2012

Keywords:

Customer Loyalty

Pair wise Comparison Matrix

RFM

AHP

TOPSIS

Bank

\begin{abstract}
One of the most basic requirements of financial institutes, governmental and private banks in the present age is to have a good understanding on customers' behaviors of bank network. It helps banks determine customer loyalty, which yields profit making for bank. On the other hand, it is important to know about credit risk of customers with the goal of decreasing loss and better allocation of bank resources to applicants of receiving loan. According to nature of customer loyalty discussion and credit risk, these two issues are separately studied. The present article deals with studying customer loyalty and prioritizing based one private bank in Kurdistan province. The proposed model of this paper studies customer loyalty by using Recency Frequency Monetary (RFM) factor for prioritizing customer based on loyalty properties and Technique for Order Preference by Similarity to Ideal Solution (TOPSIS). In addition, in order to calculate the relative importance coefficient or weight of loyalty properties in RFM method, the pair wise comparison matrix based on analytical hierarchy process (AHP) is used. Results show that in the present study, necessarily customers having higher average monetary value during a specified time period does not have much higher priority compared with other customers.
\end{abstract}

\section{Introduction}

Nowadays experts for banking research believe that developing global trade depends on developing electronic trade. It also depends on electronic banking using suitable models and techniques results in improving banking activities and successful presence of financial institutes and banks in the field of competition and global trade. Financial institutes especially banks under today's business competition environment are facing with great problems and environmental-economic changes, which results in complicating activities and developing technology. In addition, global economy results in severe competition at business environment. Therefore, attracting new customers and keeping present customers is very importance. Therefore, according to excellent status of customer in such systems, we observe organizations; in which, their first priority is customer orientation and have selected customer relationship management (CRM) as method for being successful. 
During the past few years, banking industry in Iran has faced with severe competition and according to ever-growing process of privatization and increasing level of competition in this field; there is great attention toward customer orientation. It is obvious that those banks are more successful, in addition to attempt for keeping their present customers, that they attempt to offer suitable service to attract new customer and obtain profitability.

In order to obtain this goal it is necessary to recognize behavioral properties and requirements of customer at bank network and attempt to improve customer satisfaction. In addition, according to different values of each customer at bank network, it is required to recognize valuable customers, compiling suitable plans and strategies for offering better services attempting to improve customer loyalty. Obtaining this goal; results in increasing profitability and long-term success of bank. On the other hand, according to descending process of monetary value and bank resources, it is required to make decision in associated with better allocation of bank resources. On the other hand, due to technological advancement and developing electronic banking, meeting all tastes and requirements of customer at bank network is not simple task. Therefore, bank shall continue depending on their competitive advantage and meeting requirement of their customer in order to be successful to continue their survival.

\section{Problem definition}

Studying performance of other countries indicates that investment and level of economic advancement has close relationship together i.e. countries having effective pattern for allocating and equipping bank resources, generally have higher level of economic advancement and consequently, higher social welfare. Equipping and allocating investment resources at economic activities is indicated through financial markets. Meanwhile, recognizing customers and correct understanding their clusters has great importance for keeping and increasing customer satisfaction and loyalty (Madhooshi, 2007). Banks due to nature of their working processes require having suitable customer relationship management (CRM).

Many of the today's banks do not have correct understanding from their customer requirements and most of their approaches are traditional. Many banks are still not able to put their customers as their first priority based on correct scientific models. Therefore, the present research attempts to identify customer satisfaction and loyalty based on RFM model and these factors (customer satisfaction and loyalty) were calculated at one private bank in Kurdistan province. Several researches have been performed in this field by studying research literature (Albadavi \& Ghapanchi, 2005). The lack of using CRM techniques at governmental and private banks of Iran is among the most important reason for failure of Iranian banks to keep their customer. Gap between productivity of banking industry in Iran and world's modern banking industry indicates great difference between banking industry of Iran with international standards that is as a result of several factors. Lack of applying different techniques for effective using from bank resources, results in inefficiency of banking activities; since, allocating limited resources is not performed suitably and decreasing profitability of banks, results in losing customer satisfaction (Asgharizadeh \& Amin, 2005). A quick look at status of banking activity in Iran discloses that Iranian banks with respect to level and quality of offering service have very little amount of advancement in comparison to other developed countries (Rouhi, 2004).

CRM as effective tool may have considerable role for improving quality of banking processes. CRM is concentrated business strategy that integrates marketing activities, sale and customer support on dynamic basis (Chalmeta, 2006). This method attempts to improve customer value for business processes and the way of communication with customer by developing integration of process (Ashridge Group, 2006). Obtaining customer loyalty is the final goal of customer relationship management. Loyalty is obtained when value with respect to point of customers and their experiences are mixed together and results in relating business processes with customers. Business process in $\mathrm{CRM}$ is based on a principle, which includes targeting for each single customer, attracting and 
keeping customer loyalty and selecting customer based on customer lifetime value (Rygielski et al., 2002). Therefore, the most important advantage of CRM is improving profitability, economizing and decreasing costs summarized at inner and outer organizational influences (Elahi \& Heidari, 2005). CRM is studied and implemented based on several techniques used at previous researches in the field of banking including: customer clustering techniques, modeling customer behavior, recognizing important customers, analyzing risk and calculating previous profitability.

It is to be noted that the most important application of CRM is analysis of banks and customer clustering with the goal of recognizing important customers and offering privilege to customers. One of the studies in relation to customer clustering at banking industry was article offered by Alfanesi and Sejernt (2000), which deals with studying clustering bank customer at Indonesia based on anthropology variable and desired advantages of customers as they used from hierarchical clustering, clustering databank and K-means method for clustering customers. In addition Maenpa (2006) in his study referred to this issue that clustering customers in the field of Internet banking is performed based on anthropological properties and principal indices of facilitation for banking, security, job opportunity and investment exchanges. Machauer and Moorgner (2001) studied anthropological criteria and their relationships with approach and customer expectation for clustering customers of bank. In addition Alencar et al. (2006), Cheng and Chan (2009), Chen et al. (2009), Chai and Chan (2008) and McCarty and Hastak (2007) offered several articles in the field of application of RFM mode for clustering customers.

The primary goal of these articles is to apply heuristic and meta-heuristic approaches and techniques for forecasting the weight of RFM factors and improving performance of customer clustering methods by using aforesaid model. In addition; Secme et al. (2009), Wu et al. (2009) and $\mathrm{Hu}$ and Liao (2011) considered the multiple criteria decision making (MCDM) models for prioritizing factors in performance evaluation models and for ranking the bank branches in their researches.

\section{Conceptual model of research}

As it was already mentioned at previous sections of research, the goal is to recognize and select properties of customer loyalty and their priority at one the private banks of Kurdistan province. On this basis data associated with current bank account of 100 customers of bank during time period of 24 months ended to March, 20, 2010 is used. According to the statements of bank managers, these customers were among trustful customers and the goal of bank was to recognize and prioritize behavior properties and tastes of customers in order to select suitable strategies to keep customers. On this basis, data of customer were collected as follows: account number, sex, marital status, and date of birth, number of days referring to bank, education, and level of transaction. The desired stages for obtaining goal of research are as follows,

a) Collecting customer's data

b) Eliminating additional data and preparing require data

c) Calculating variables of RFM model for single customers under study

d) Calculating the weight of RFM variables based on pairwise comparison matrix in AHP model.

e) Ranking and prioritizing the studied customers based on RFM criterion and their weights by TOPSIS Model.

\subsection{RFM Model}

The analysis of Recency Frequency Monetary (RFM) is recently changed into Recency Frequency Value (RFV). It has been used for over 50 years in direct marketing to determine target customers, to 
decrease the cost of sending message and increasing profit (Kohavi \& Parikh, 2004). This analysis has great application in the field of bank and its special units such as electronic banking (McCarty \& Hastak, 2007). The primary objective of RFM is to obtain a simple working framework for quantifying customer behavior. Customers after allocating a grade of RFM can be grouped to different sections and then to analyze their profit. Results of this basic analysis show that it is used for making decision in relation to recency of customer relationship.

Chen et al., (2009) studied the used RFM models for marketing literature. They defined a clustering framework to make valuable information about customer behaviors to aid manager's decision making. Liua \& Shih (2005) used the weighted RFM model to improve orders performing based on E-commerce application and customer life-time value. RFM is the most famous models for analyzing customer value. Advantage of this model is that it extracts properties of customer by using few criterions as properties of cluster (3 criterions) consequently; complexity of model for analyzing customer lifetime value is decreased. In addition to customer behavior point of view, RFM model is a very common method for measuring level of customer relationship. Note that the cost of keeping customer is higher than cost of attracting a new customer. In this method according to 3 criterions of delay or recency, frequency and level of cash a privilege is offered to customer (Cheng \& Chan, 2009).

Recency: recency or the last purchase is shown by R refers to gap between final purchase and the present time. The lower recency the greater $\mathrm{R}$

Frequency: frequency is shown by $\mathrm{F}$ that refers to number of purchase at time period. The greater frequency the greater $\mathrm{F}$

Monetary Value: monetary value is shown by $M$ and refers to amount of money that is spent by customer during a specified time period. The greater monetary value the greater $\mathrm{M}$

RFM analytical method is used for different jobs and fields. Therefore, it is possible to say that RFM refers to different issues among various people. One of the principal policies of RFM analysis is that the things recognized as Hard Coding. Hard coding means to allocate weight to each of the variables including: recency, frequency and monetary value that may result in privilege for each of the persons attending at data bank. Allocating weight is generally functioning of judgment and offering comment of data bank of marketers in relation to special data bank. Weights may be based on suggestions and demands that are already referred.

Acting based on previous data results in making immediate and exact decision. It is possible to say that it is used applied from 3 following methodologies at RFM: Ordinary method or even ranking, Hughes method and weighted RFM. Each of the aforesaid methods shall be selected during appropriate time period. Then we collect customer's information in this period, which includes average monetary value at any time period, number of referring to bank, final time of referring to bank. This task is called data preparing. These data is mixed by using 3 methods including: ordinary Hughes and weighted RFM and offer point to customers. The present article deals with offering weighted RFM method and so for calculating weights, pairwise comparison matrix based on AHP model has been used.

\subsection{Pair wise Comparison Matrix and AHP Method}

In this research by collecting comment of several experts and applying relative modern method of AHP as effective method for decision making, it is possible to offer weight to factors and priorities of customers. AHP may be summarized into 4 principal stages including: formation of hierarchy tree, pairwise comparison of variables, operation for calculating data and calculating inconsistency rate. In order to fill pairwise comparison matrix of variables in the present article, it is used from qualitative styles and changing them to numbers based on Likert spectrum to determine relative importance of each factor compared with other factors and weight of each criterion is determined by a group of 
experts. Work procedure is as follows: first, all criteria are registered at a table having 2 vertical and horizontal columns and applicant shall determine weight of each criterion by using pairwise comparison. By using Saati's Eigen vector method, weight of each criterion is calculated. While calculating an element with itself, number 1 is written in matrix. Therefore, the principal diameter of matrix is set of number 1. In order to compare other elements, we compare the first element (element available at left column of matrix) with second element (element available at top row) and to estimate its numerical value. By using inverse value of that number, it is possible to compare the second element with first element. Inconsistency rate determines level of inconsistency of comparisons. This rate shows that up to which level it is possible depending on priorities obtained from group members and mixed tables. Experience show that is inconsistency rate (CR) is less than 0.10 it is possible to accept comparison consistency. Eq. (1) and Eq. (2) are used for calculating inconsistency rate and inconsistency rate of pair wise comparison matrix,

$C . I=\frac{\lambda_{\max }-n}{n}$,

where $\lambda_{\max }$ is largest Eigen value for pair wise comparison matrix, $n$ is sum of Eigen value for pair wise comparison matrix and RI is criterion for random inconsistency.

$C R=C I / R I$

\subsection{Techniques for Order Preference by Similarity to Ideal Solution (TOPSIS)}

Yung and Hung offered TOPSIS, which means that selecting an Alternative shall find shortest distance from ideal solution and also farthest distance from negative ideal solution. Assume that utility of each criterion has monotonous increase (decrease) i.e. criterions only have positive or negative aspect. Criteria having positive aspect are profit and the criteria having negative aspect are cost components. Therefore, it easily possible to determine ideal solution as the best value of a criterion indicates that criterion is ideal and the worst value indicates negative ideal. From geometrical point of view, estimation attempts to observe desired choice; in which, minimum Euclidian distance from ideal solution and simultaneously farthest distance from ideal solution. TOPSIS studies both distance of the Alternative to positive and negative solution simultaneously through relative similarity to ideal solution. TOPSIS method evaluates decision making matrix, which includes $m$ choices and $n$ criteria. In this matrix, the criteria having positive property are regarded as profit and the criteria having negative aspect are cost. In addition, any result mentioned in matrix shall be quantified and whereas criteria of DM do not have the same importance, DM offers the weights for these criteria. On this basis, this process attempts to normalize the utilities in decision making matrix as follows,

$$
r_{i j}=\frac{X_{i j}}{\sqrt{\sum_{i=1}^{m} X_{i j}^{2}}}
$$

The weights $\mathrm{w}=\left\{\mathrm{w}_{1}, \mathrm{w}_{2}, \ldots \mathrm{w}_{\mathrm{j}} \ldots \mathrm{w}_{\mathrm{n}}\right)$ for criteria with $\sum_{i=1}^{n} w_{j}=1$ are determined by DM based on different methods including analytical hierarchy process (AHP). Then by multiplying $\mathrm{j}^{\text {th }}$ column from normalized decision making matrix with the weight of $j^{\text {th }}$ criteria $\left(w_{j}\right)$, the weighted normalized matrix $V$ is obtained. Then, the positive and negative ideal solutions are defined as follows,

$$
\begin{aligned}
& A^{*}=\left\{\left(\max v_{i j} \mid j \in J\right),\left(\min v_{i j} \mid j \in J^{\prime}\right) \mid i=1,2, \ldots, m\right\}=\left\{v_{1}^{*}, v_{2}^{*}, \ldots, v_{j}^{*}, \ldots, v_{n}^{*}\right\} \\
& A^{*}=\left\{\left(\min v_{i j} \mid j \in J\right),\left(\max v_{i j} \mid j \in J^{\prime}\right), \mid i=1,2, \ldots, m\right\}=\left\{v_{1}^{-}, v_{2}^{-}, \ldots, v_{j}^{-}, \ldots, v_{n}^{-}\right\}
\end{aligned}
$$

Profit criteria: $j \mapsto J=\{j=1,2,3, \ldots, n\}$

Cost criteria: $j \mapsto J^{\prime}=\{j=1,2,3, \ldots, n\}$ 
Distance of each alternative with positive and negative ideal alternatives by Euclidian method and Eq. (6) and Eq. (7) are measured as follows:

$$
\begin{aligned}
& S_{i^{*}}=\sqrt{\sum_{j=1}^{n}\left(v_{i j}-v_{j}^{*}\right)^{2}} \quad i=1,2,3, \ldots ., m \\
& S_{i-}=\sqrt{\sum_{j=1}^{n}\left(v_{i j}-v_{j}^{-}\right)^{2}} \quad i=1,2,3, \ldots ., m
\end{aligned}
$$

Criteria of relative similarity of choice $\mathrm{A}_{\mathrm{i}}$ to ideal solution is obtained as follows,

$$
C_{i^{*}}=\frac{S_{i-}}{S_{j^{*}}+S_{i-}}
$$

$0 \prec C_{i^{*}} \prec 1 \quad i=1,2,3, \ldots, m$

It is observed that $A_{i}=A^{*}$ then $C_{i}=1$ and if $A_{i}=\bar{A}$ then $C_{i}=0$

Then if distance of Alternative $A_{i}$ from ideal solution $\left(A^{*}\right)$ is more near, $C_{i}$ is more near to 1 . Finally based on $\mathrm{C}_{\mathrm{i}}$ it is possible to rank available choices.

\section{Calculating variables of RFM Mmodel for customer under study}

As it was described at RFM model, variables including recency (R) frequency $(\mathrm{F})$ and monetary value (M) are regarded as basis for customer loyalty to banking network. On this basis amount of these variables for customer of this bank are separated and calculated and then formula are normalized to be compared. Note that normalizing M, F variables are based on Eq. (9) and variable R is based on Eq. (10), as follows,

$$
\begin{aligned}
& X^{\prime}=\frac{\left(X-X^{L}\right)}{X^{U}-X^{L}}, \\
& X^{\prime}=\frac{X^{U}-X}{X^{U}-X^{L}},
\end{aligned}
$$

where $X$ is non-normalized principal variable and $X^{L}-X^{U}$ is the greatest and the smallest variable under non-normalized mode. By using aforesaid formula, the normalized amounts the 3 variables including R,F, $M$ are customers fall within 0,1 range. Results show that customers in our study are among valuable loyal customer; therefore, $M$ normalized amount is very similar together. In addition normalized amounts $R$ have continuous relationship with bank; therefore, dispersion around axis 1 is very high. Meanwhile, higher fluctuation under normalized amount is seen at $F$ variable.

\section{Calculating importance coefficient or weight of RFM variables}

As we mentioned earlier, weight or importance coefficients of 3 principal variables of RFM model at this research are calculated based on pairwise comparison technique based on AHP model. Pair wise comparison of these 3 variables was performed by 12 experts of banking network within pair wise comparison matrix and the results are summarized in Table 1 . Note that consistency ratio is less than $0.1 /$

\section{Table 1}

Sample of pairwise comparison matrix at RFM model

\begin{tabular}{llll}
\hline & & $\mathrm{j}$ & \\
\hline $\mathrm{i}$ & $\mathrm{R}$ & $\mathrm{F}$ & $\mathrm{M}$ \\
\hline $\mathrm{R}$ & 1 & 0.5 & 0.2 \\
\hline $\mathrm{F}$ & 2 & 1 & 0.33 \\
$\mathrm{M}$ & 5 & 3 & 1 \\
\hline
\end{tabular}


The weight of 3 variables of RFM calculated based on Saati's Eigen Vector method and inconsistency rate for pair wise comparison matrix is obtained based on AHP model. Pair wise comparison matrix is obtained based on making decision of a group of experts according to Table 2; in which, inconsistency rate of this matrix is at acceptable rate.

Table 2

Group pair wise comparison matrix of factors at RFM model

\begin{tabular}{llll} 
& & $\mathrm{j}$ & \\
\hline $\mathrm{i}$ & $\mathrm{R}$ & $\mathrm{F}$ & $\mathrm{M}$ \\
\hline $\mathrm{R}$ & 1 & 0.543 & 0.170 \\
\hline $\mathrm{F}$ & 1.84 & 1 & 0.269 \\
$\mathrm{M}$ & 5.89 & 3.72 & 1 \\
\hline
\end{tabular}

According to weight of $M, F, R$ variables and based on this matrix and Saati's Eigen Vector method, the following calculation is obtained.
$W_{R}=0.112$
$W_{F}=0.196$
$W_{M}=0.692$

\section{Ranking customer based on properties of customer loyalty at RFM model}

As it was mentioned at description of TOPSIS method at section 3.3, customers at this study are compared and ranked according 3 variables of recency, frequency $(F)$ and monetary value $(M)$ by observing weights obtained at section 5 . As it was already mentioned at section 4 , amount of these 3 variables are calculated for each customers; consequently, customers by applying suitable weights and desired criterions are prioritized within TOPSIS model.

Table 3

The distance of Alternatives to positive/negative ideal solution and ideal similarity index

\begin{tabular}{llll}
\hline Customer & $d_{i}^{+}$ & $d_{i}^{-}$ & $\mathrm{C}_{\mathrm{i}}$ \\
\hline 1 & 0.326 & 0.177 & 0.352 \\
2 & 0.284 & 0.144 & 0.336 \\
3 & 0.197 & 0.291 & 0.596 \\
4 & 0.361 & 0.248 & 0.291 \\
5 & 0.219 & 0.252 & 0.535 \\
6 & 0.087 & 0.283 & 0.765 \\
7 & 0.192 & 0.342 & 0.640 \\
8 & 0.389 & 0.089 & 0.186 \\
9 & 0.094 & 0.149 & 0.613 \\
10 & 0.063 & 0.359 & 0.851 \\
\hline
\end{tabular}

Note that variable $R$ is regarded as negative criterion since great amount of this variable indicates less relationship of customer with bank; meanwhile, $M$ and $F$ represent positive criterion. Therefore, in section 4 the method of normalizing these factors was different; however, in TOPSIS method, whereas normalized amounts are used at this variable; therefore, all 3 indices are regarded as positive criterion. Table 3 shows distance of Alternatives from positive and negative ideal solutions $\left(d_{i}^{-}, d_{i}^{+}\right)$ and similarity criterion to ideal choice $(\mathrm{Ci})$ is shown. It is obvious that greater amount of index for similarity of to ideal solution (Ci) shows higher loyalty and value of customer. On this basis, Table 3 shows priority of customers based on ideal similarity criterion.

\section{Conclusion}

In the today's business and economy world, the banking industry's success depends on recognition and behavioral properties of customer, keeping available customers through selecting suitable strategies and attracting new customers through offering new and diverse services. Therefore, the present research deals with recognizing properties of customer loyalty based on RFM model by 
applying importance coefficient for these variables. As it was already mentioned, properties of this model are recency $(R)$ frequency $(F)$ and monetary value $(M)$. Therefore, relative importance coefficient or weights of these criteria have been calculated using AHP model. We have used TOPSIS to prioritize all alternative based on the criteria. Results show that $30 \%$ of costumers having 1 to 20 ranks at this study are customers with monetary value less than total average monetary value. This reveals that in spite of more importance of variable as monetary value compared with other variables, the effects of other variables are so that this class of customers may have higher priority because of having higher frequency.

\section{References}

Albadwi, A., \& Ghapanchi, A. (2006). Using of data mining for implementation of customer relationship management in banking industry. Commercial Surveys, 14, 85-81.

Alencar, A., Ribeiro, E., Ferreira, A., Schmitz, E., Lima, P., \& Manso, F. (2006). Optimized RFM analysis. Marketing Intelligence \& Planning, 24(2), 106-118.

Alfanis, L., \& Sergeant, A. (2000). Market segmentation in the Indonesian banking sector: the relationship between demographics and desired customer benefits. International Journal of Bank Marketing, 18(2), 64-74.

Ashridge Group (2006). Customer Relationship Management. USA, Ashridge Group Publishing.

Asgharizadeh, A., \& Amin, F. (2006). Increasing productivity of banking services with customers priority using of quantities techniques. Journal of Economic Policy and Research, 36.

Chai, C., \& Chan, H. (2008). Intelligent value-based customer segmentation method for campaign management: A case study of automobile retailer. Expert Systems with Applications, 34(4), 2754-2762.

Chalmeta, R. (2006). Methodology for customer relationship management. Journal of Systems and Software, 79(7), 1015-1024.

Chen, Y.L., Kuo, M.H., Wu, S.Y., \& Tang, K. (2009). Discovering recency, frequency, and monetary (RFM) sequential patterns from customers' purchasing data. Electronic Commerce Research and Applications, 8(5), 241-251.

Cheng, C.H., \& Chan, Y.S. (2009). Classifying the segmentation of customer value via RFM model and RS theory. Expert Systems with Applications, 36(3), 4176-4184.

Elahi, S., \& Heydari, B. (2006). Customer Relationship Management. Tehran: Printing and Publishing of Commercial, Commercial Research.

Hu, Y.C., \& Liao, P.C. (2011). Finding critical criteria of evaluating electronic service quality of Internet banking using fuzzy multiple-criteria decision making. Applied Soft Computing, 11(4), 3764-3770.

Kohavi, R., \& Parikh, R. (2004). Visualizing RFM Segmentation. SIAM: Society for Industrial and Applied Mathematics.

Liua, D.R., \& Shih, Y.Y. (2005). Hybrid approaches to product recommendation based on customer lifetime value and purchase preferences. Journal of Systems and Software, 77(2), 181-191.

Machauer, A., \& Moorgner, S. (2001). Segmentation of bank customers by expected benefits and attitudes. International Journal of Bank Marketing, 19(1), 6-17.

Madhooshi, M. (2007). Developing an integrated model for calculating the customer lifetime value. The $4^{\text {th }}$ International Management conference.

Maenpaa, K. (2006). Clustering the consumers on the basis of their perception of the internet banking services. Internet Research, 16 (3), 304 - 322.

McCarty, J., \& Hastak, M. (2007). Segmentation approaches in data mining: A comparison of RFM, chaid and logistic regression. Journal of Business Research, 60(6), 656-662.

Roohi.Z, A. (2011). Quality services of responding to customer needs. Mellat Partow Magazine, 50.

Rygielski, C., Wang, J.C., \& Yen, D.C. (2002). Data mining techniques for customer relationship management. Technology in Society, 24(4), 483-502.

Seçme, N.Y., Bayrakdaroğlu, A., \& Kahraman, C. (2009). Fuzzy performance evaluation in Turkish Banking Sector using Analytic Hierarchy Process and TOPSIS. Expert Systems with Applications, 36(9), 11699-11709.

Wu, H.Y., Tzeng, G.H., \& Chen, Y.H. (2009). A fuzzy MCDM approach for evaluating banking performance based on Balanced Scorecard. Expert Systems with Applications, 36(6), 10135-10147. 